\title{
A New Self Microemulsifying Mouth Dissolving Film
}

\author{
Seema Venkatrao Pattewar ${ }^{1}$, Sanjay Bhaskar Kasture', Vishal Vivek Pande ${ }^{2}$, Swapnil K. Sharma1 \\ 1Department of Pharmacy, Banasthali University, Banasthali, Rajasthan, INDIA. \\ ${ }^{2}$ Sanjivani College of Pharmaceutical Education and Research, Kopargaon, INDIA.
}

\begin{abstract}
A self micro-emulsifying mouth dissolving film (SMMDF) is a dosage form which is based on mouth dissolving film integrated with self micro emulsifying components. Stability of self-micro emulsifying drug delivery system is one of major problem of lipid based drug delivery system. This can be minimized by converting liquid self micro emulsifying drug delivery system into solid SMMDF. This drug delivery system enjoys both advantages of self micro emulsifying drug delivery system (SMEDDS) along with mouth dissolving film (MDF). Self micro-emulsifying mouth dissolving film formulations can be used to improve the oral bioavailability of hydrophobic drugs due to their efficiency of presenting the hydrophobic drug in solubilized form. This review article tries to describe the formulation of MDF and also talks about the SMEDDS. Some of the patented preparations of SMEDDS are also listed.
\end{abstract}

Keywords: Bioavailability, Lipid based drug delivery system, Mouth dissolving film, Self micro emulsifying drug delivery system and Self micro-emulsifying mouth dissolving film.

\section{INTRODUCTION}

Systemic absorption of drug is based on factor such as route of administration for a drug. Parenteral administration has some disadvantages such as it requires strict aseptic procedures for preparation. Parenteral route gives pain at the site of injection. Administration of drug by oral route is the most effective, non-invasive, adaptable, and acceptable route. Oral route has better therapeutic efficacy, low cost and good patient compliance. ${ }^{1}$ In the oral cavity, the delivery of drug may be by intraoral sublingual, intraoral buccal, and peroral. Intraoral sublingual is administration through the mucosa of mouth below the tongue. Intraoral buccal is passage through the mucosa of cheeks and peroral is passage through the mouth to the gastrointestinal tract (GI tract).

The peroral route is commonly used. Certain drug after peroral administration gets hydrolyzed due to acid in stomach. Some drugs may degrade due to enzymes, some drug gets pre-systemic metabolism. These can reduce bioavailability. The insolubility, hydrophobic nature of certain drug may reduce their absorption. Intraoral route has many advantages over peroral route.

1. The oral mucosa is rich in blood vessels that do not drain into the portal circulation. Drug directly enters the systemic circulation by the jugular vein. Thus avoiding first pass effects. ${ }^{2}$

2. Intraoral route causes increased absorption of drug, it has fast onset of actions and good bioavailability.

3. Intraoral route does not require swallowing.

4. Intraoral route does not produce gastrointestinal irritation.

By sublingual route, drugs get the epithelium barrier of the oral mucosa. A phospholipid membrane of upper epithelial cells forms a protective barrier. The lipophilic drug can pass through phospholipid membrane. Passive diffusion is responsible for
Submission Date : 18-04-2016 Revision Date : 20-06-2016 Accepted Date : 12-07-2016

DOI: 10.5530/ijper.50.3.29

Correspondence:

Seema V Pattewar,

Department of Pharmacy,

Banasthali University,

Banasthali,

Rajasthan-304022, INDIA. Mobile No: 9970069921.

E-mail: tsdpatil99@gmail. com

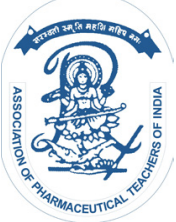

www.ijper.org 


\begin{tabular}{|c|c|c|}
\hline Ingredient & Amount & Uses (Example) \\
\hline Drug & $5-30 \% w / w$ & All drug with low dose \\
\hline Water soluble polymer & $45 \% \mathrm{w} / \mathrm{w}$ & $\begin{array}{c}\text { Film forming capability (HPMC E3, E5, E6, E15, K3, Methyl cellulose } \\
\text { A3, A6, A15, Pullulan, Polyvinyl pyrollidon K-90, Pectin, gelatin, } \\
\text { Sodium alginate, Hydroxy propyl cellulose, Polyvinylalcohol, } \\
\text { Maltodextrin) }\end{array}$ \\
\hline Plastisizers & $0-20 \% w / w$ & $\begin{array}{l}\text { Increases the flexibility and reduces the brittleness of film (Glycerol, } \\
\text { Polyethylene gycol, Dibutylpthallate,triethyl citrate) }\end{array}$ \\
\hline Surfactant & q.s. & $\begin{array}{l}\text { They are used as solubilizing and wetting agents making the } \\
\text { film to dissolve rapidly within seconds(Tween } 80 \text {,Sodium lauryl } \\
\text { sulphate,benzalkonium chloride) }\end{array}$ \\
\hline Sweetning agent & $3-6 \% w / w$ & $\begin{array}{l}\text { Increasing the palatability of the film (Aspartame, } \\
\text { Saccharin,Cyclamate,Alitame and Neotame, Acesulfame-K) }\end{array}$ \\
\hline Saliva stimulating agent & $2-6 \% w / w$ & $\begin{array}{l}\text { Increases the saliva stimulation for faster dissolution of film (Citric } \\
\text { acid, Malic acid) }\end{array}$ \\
\hline Colors, Flavours & $\begin{array}{c}\text { should not } \\
\text { exceed } 1 \% \mathrm{w} / \mathrm{w}\end{array}$ & $\begin{array}{l}\text { Pigments like titanium dioxide, silicon dioxide are used as prominent } \\
\text { coloring agents.Fruity flavors like cocoa, chocolate and fruit essence } \\
\text { like apple, raspberry and cherry are most widely used. Essential oils } \\
\text { like eucalyptol and thymol. }\end{array}$ \\
\hline
\end{tabular}

drug to cross the cell membrane. Transfer of drug is proportional to the difference in concentration and solubility, carried into the epithelial membranes. The transfer by the oral mucosa is related to molecular size and ionization. Un-ionized molecules or molecules that have neutral electrical charge give more absorption. The orally disintegrating tablet or $\mathrm{ODT}^{3}$ meets the European Medicines Agency recommendation. Administration of ODTs is easy and there is no need to swallow large particles or water. The required disintegration time of ODTs has to be less than 30 seconds which needs much care during the manufacturing. Compression force and hardness of the tablet are critical parameters of manufacturing of ODTs. Compression force is too high then disintegration time increases than the established limit. Compression force is low then mechanical properties of the tablet will be weak. It gives fragile and brittle tablets of low resistance to mechanical shocks. The most recent researches in the field of orally dissolving solid dosage forms have been dealing with oral thin film technology (OTF) which is a relatively new area of interest in the oral administration. The first commercial success of oral thin films appeared in the United States (Listerine Pocket Paks). Nowadays several products, manufactured by this technology, have reached the market or are in the clinical phase of development. OTFs have some advantages over ODTs. The mechanical properties of the films are better than those of ODTs due to their flexibility. OTFs have higher surface for contact with the saliva, so dissolution can be faster. ${ }^{4}$ OTFs have an established shelf-life of 3 years, depending upon drug but are sensitive to moisture. ${ }^{5}$ The various synonyms used for Fast dissolving films (FDFs) include mouth dissolving films (MDFs), melt in-mouth films, oro-dispersible, quick dissolving and rapid disintegrating films, orally disintegrating films (ODFs), ${ }^{6,7}$ orally dissolving strip. ${ }^{8}$

Mouth dissolving film: The oral films are essentially complex polymeric matrices that can use efficiently as drug delivery system. These polymeric matrix are composed by several components in order to achieve well designed drug-delivery. Table 1 gives idea about composition of fast dissolving film.

A fast-dissolving film is a film containing drug that dissolves or disintegrates in the saliva remarkably fast, without the need for water or chewing. Some drugs are absorbed well from the mouth, pharynx and oesophagus as the saliva passes down into the stomach. The bioavailability of drug is significantly improved. Mouth dissolving film typically designed for oral administration, with the user placing the strip on or under the tongue or along the inside of the cheek.

\section{Classification of mouth dissolving strips: ${ }^{9}$}

1) Mucoadhesive melt-away wafer: Mucoadhesive film is applied to buccal and gingival mucosa and sticks to mucosal surface. Mucoadhesive films are categorized in two parts.

(A) Mucoadhesive melt away strip- It sticks to the mucosa; totally dissolve within few minutes and continuously release the drug over time. (B) Mucoadhesive sustained release film-This type of film sticks to mucosa and remain there for several hours.

2) Flash release wafers: Flash release wafers dissolve in maximum of 60 seconds and immediately release the drug in oral cavity. As per the site of application, 
Table 2: Characteristics of SEDDS, SMEDDS

\begin{tabular}{|c|c|c|}
\hline $\begin{array}{c}\text { System/ } \\
\text { characteristic }\end{array}$ & SEDDS & SMEDDS \\
\hline \multirow[t]{2}{*}{ Composition } & A system with a drug, oil, surfactant. & $\begin{array}{l}\text { A system with drug, oil, surfactant, co- } \\
\text { surfactant/ hydrophilic co-solvent. }\end{array}$ \\
\hline & \multicolumn{2}{|c|}{ SEDDS, SMEDDS, form a fine oil-in-water micro emulsion with GI fluids. } \\
\hline Droplet size in dispersion & $200 \mathrm{~nm}$ to $5 \mu \mathrm{m}$. Turbid appearance. & $\begin{array}{c}\text { Less than } 200 \mathrm{~nm} \text {. Clear to translucent in } \\
\text { appearance. }\end{array}$ \\
\hline Solubilizing capacity & \multicolumn{2}{|c|}{ SEDDS, SMEDDS have high drug solubilizing capacity. } \\
\hline Stability of dispersions & $\begin{array}{l}\text { Thermodynamically } \\
\text { unstable. }\end{array}$ & $\begin{array}{l}\text { Thermodynamically } \\
\text { stable }\end{array}$ \\
\hline \multirow[t]{2}{*}{$\begin{array}{l}\text { Formulation } \\
\text { technique }\end{array}$} & $\begin{array}{l}\text { Ternary phase diagram is require to optimize of } \\
\text { SEDDS. }\end{array}$ & $\begin{array}{c}\text { Pseudo-ternary phase diagram is require to } \\
\text { optimize SMEDDS. }\end{array}$ \\
\hline & \multicolumn{2}{|c|}{$\begin{array}{l}\text { SEDDS, SMEDDS formulations can be prepared as liquids and semi-solids for capsule, tablet } \\
\text { manufacturing. }\end{array}$} \\
\hline Concentration of oil & $40-80 \%$ & less than $20 \%$ \\
\hline Surfactant (HLB) & Surfactants of HLB $<12$. & Surfactants of HLB $>12$. \\
\hline
\end{tabular}

the flash release wafers are categorized in two parts. (A) Orodispersible film (ODF) - The ODF is ultra thin strip, which is similar to postage stamp in shape and size. (B) Sublingual films - Formulation of these types of films is same as ODFs. These films are placed under a tongue rather than in oral cavity.

\section{Self micro-emulsifying mouth dissolving film (SMMDF)}

A Self micro-emulsifying mouth dissolving film (SMMDF) is a new dosage form. Only one paper is found during literature survey. That paper is published by Xiao L, College of Pharmaceutical Sciences, Southwest University, Chongqing, China. In India no such work is observed up till now. SMMDF is based on mouth dissolving film integrated with self microemulsifying components. SMMDF has great potential for enhancing oral dissolution and bioavailability of poorly water soluble drug. Previously this solid SMEDDS prepared by incorporating a liquid SMEDDS into a soft gelatin capsule or hard gelatin capsule and presented as a solid dosage form, but due to migration of surfactant in shell may result in drug precipitation. For poorly water soluble drug, novel SMMDF is the best option. Researchers showed that SMMDF maintained the absorption characteristics of liquid SMEDDS.2

One of the major problems to drug formulation development is poor water solubility of new drug. More than $40 \%$ of all new drugs are poorly water soluble. ${ }^{10}$ Poor solubility and ultimately low dissolution rate of these drugs in the gastro-intestinal fluids cause poor bioavailability. For BCS class II drugs, the bioavailability may be enhanced by increasing the solubility and dissolution rate of these drugs in the gastro-intestinal fluids. ${ }^{11}$

Lipid-based drug delivery system (LBDDS) plays an important role in the delivery of hydrophobic drugs with low bioavailability by using lipids as carriers. ${ }^{12}$ Lipidbased drug delivery systems have gained considerable interest after the commercial success of Sand immune Neoral, Novartis Pvt. Ltd., Fortovase and Roche Laboratories Inc with much attention focused on self micro-emulsifying drug delivery systems (SMEDDS). SMEDDS systems are composed of oil, surfactant and co surfactant. Upon mild agitation followed by dilution in an aqueous medium (gastrointestinal fluids), this system can form fine oil-in-water $(\mathrm{o} / \mathrm{w})$ microemulsion. The small droplet size provides a large surface area for drug release and absorption. ${ }^{13}$ SMEDDS enhances drug dissolution and improves stability of drug. ${ }^{14}$ SMEDDS has great ability to enhancing oral bioavailability of poorly water soluble drugs. Droplet size is increases as the quantity of oil in SMEDDS formulation increases. ${ }^{15}$ The absorption after oral administration of the drug from SMEDDS depends on surfactant concentration, oil/surfactant ratio, charge and droplet size. ${ }^{16}$ SMEDDS with Labrafil as oil, propylene glycol as surfactant and Cremophor RH40 as co surfactant have provided the greatest bioavailability. ${ }^{17,18}$ Pseudo-ternary phase diagrams have been used to evaluate the micro emulsification area. ${ }^{19}$ Self emulsifying drug delivery systems (SEDDS) also comes under the LBDDS. SEDDS has different characteristics. Information about characteristics of SEDDS, SMEDDS is depicted in Table 2.

Formulation of SMEDDS: The synthetic hydrophilic oils and surfactants provide good solu- 
bility to hydrophobic drugs than conventional vegetable oils. Ethanol, Propylene glycol and Polyethylene glycol also contribute for the improvement of drug solubility in lipid vehicle.

Find solubility of the drug in different oil, surfactants and co-surfactant: Determine solubility by adding excess amount of drug in small vials containing $2 \mathrm{ml}$ of selected oil, surfactant and co-surfactant separately. The drug mixed with glass rod. Then the vials kept for sonication about 2 hours. The vials are tightly close and continuously stirred for 72 hours in orbital shaking incubator at $25^{\circ} \mathrm{C}$. Then centrifuge at $3500 \mathrm{rpm}$ for 20 minutes. The $1 \mathrm{ml}$ supernatants are separated and dissolve in methanol or alcohol and solubility is quantified by UV-spectrophotometer at specific wavelength after appropriate dilution with methanol or alcohol.

Select oil, surfactant and co solvent: Based on the solubility of drug oil, surfactant and co solvent is selected.

Select ratio of surfactant to co-surfactant: Fixing the surfactant/co-surfactant ratio as $1: 1$ is a better choice for the stability of SMEDDS.

Construction of Phase Diagram: Construct phase diagrams to obtain the proportion of components that can result in maximum microemulsion existence area. Chemix software can be used for this. Construct diagrams with oil, surfactant/co-surfactant (Smix) and water (pseudo-ternary phase diagram) by using water titration method at room temperature. The procedure consists of preparing solutions containing different ratio of surfactant to co-surfactant by weight such as 1:1, 2:1, 3:1 etc. Mix solutions by vortex shaker for 5 minutes and place at $50^{\circ} \mathrm{C}$ for 1 hour. Then an isotropic mixture can obtain. Each of these solutions used for preparing a mixture containing oil and Smix (mixture of surfactant and co-surfactant) in the following ratios by weight: 1:9, 2:8, 3:7, 4:6, 5:5, 6:4,7:3, 8:2, 9:1. Then mix with vortex mixer for 5 minutes and place in an oven at $50^{\circ} \mathrm{C}$ for 1 hour. All the mixtures then place at room temperature for 24 hours. Add water from 5\% to $95 \%$ to the mixture. Stir on magnetic stirrer. After each addition of water, observe the mixture for its appearance (turbid or clear). Turbidity of the samples indicates formation of a coarse emulsion. A clear isotropic solution indicates the formation of a micro emulsion. The formation of micro emulsion regions was monitored visually for turbidity-transparency-turbidity.

Preparation of SMEDDS: Optimize ratio of surfactant to co-surfactant from the phase diagram with bigger area. Weigh surfactant and co-surfactant accurately and vortex for 5-10 minutes. Place Smix in an oven at $50^{\circ} \mathrm{C}$ for 1 hour. Add oil with different ratio to Smix. Then mix by vortex shaker for 5-10 minutes. Place in oven at $50^{\circ} \mathrm{C}$ for 1 hour to form an isotropic mixture. Add drug to these isotropic formulations and mix by vortex shaker until a clear solution is obtained. ${ }^{20}$

Mechanism for increase in absorption of drug by SMEDDS:

- In vivo solubilization of drug-Presence of lipid in gastrointestinal tract (GIT) stimulates secretion of bile salt and biliary lipid such as phospholipids and cholesterol, leads to formation of intestinal mixed micelles. This causes enhancement in solubilization capacity of GIT. Addition to lipid from formulation causes further increase in solubilization capacity.

- Increase in gastric residence time of drug-Lipid in the GIT causes delay in gastric emptying. This enables better dissolution of drug and improves drug absorption.

- Promotion of intestinal lymphatic transport of drug-Lipid enhances the lymphatic transport of lipophilic drug and enhances bioavailability via reduction in first pass metabolism.

- Affecting intestinal permeability-Lipid can change the physical barrier function of gut wall. Thus increase in permeability of drug.

- Reduced metabolism and efflux activity of drugCertain surfactant and lipid show reduction in activity of efflux transporters in the gut wall thus increase in absorption of drug. Eg. Labrasol, Cremophore EL. ${ }^{21}$

Evaluation of Liquid SMEDDS: Visual observation, phase separation of microemulsion: Each formulation of SMEDDS containing drug is diluted with $250 \mathrm{ml}$ of distilled water at $37^{\circ} \mathrm{C}$ to check visual appearance. Mix the preparation in vortex shaker for 5 minutes and store the mixture for 24 hours. Observe visually phase separation and precipitation. Use those formulations exhibiting a negligible phase separation for further study.

Self-emulsification efficiency test: Assess the self-micro emulsification efficiency of drug loaded SMEDDS using a standard USP dissolution apparatus II. Assess the self-emulsification performance of each SMEDDS visually by using different grading systems like grades $A$, B, C, D and E.

Grade A: Rapidly forming (within 1 min) microemulsion, having a clear or bluish appearance.

Grade B: Rapidly forming, slightly less clear emulsion, having a bluish white appearance.

Grade C: Fine milky emulsion formed within 2 minutes.

Grade D: Dull, grayish white emulsion having slightly oily appearance that is slow to emulsify (longer than 2 minutes). 
Grade E: Formulation, exhibiting either poor or minimal emulsification with large oil globules present on the surface. Recommend Grade A, Grade B formulation as micro emulsion when dispersed in GIT. Recommend Grade $\mathrm{C}$ for SEDDS formulations.

Thermodynamic stability test: Optimize formulations then subjected to different thermodynamic stability study tests namely centrifugation and freeze thaw cycles. $\%$ transmittance test: Reconstitute the SMEDDS with distilled water (1:100). Observe the resulting microemulsion for any precipitation. Measure $\%$ transmittance at $640.2 \mathrm{~nm}$ using UV-visible spectrophotometer.

Globule size and PDI: Determine the globule size and PDI of reconstituted drug loaded SMEDDS using Malvern Zetaseizer.

Zeta-potential: Determine the zeta potential of formulations by laser diffraction analysis using particle size analyzer (Malvern Zetasizer Nano series ZS 90 UK).

Drug Content: Determine the percentage drug content of formulations from the calibration curve by using UV.

Viscosity: Evaluate the viscosity of optimized formulation by Brookfield viscometer.

In vitro dissolution studies: Perform in vitro dissolution/drug release studies in $900 \mathrm{ml}$ of $0.1 \mathrm{~N}$ HCL using USP method (dissolution apparatus II) at $100 \mathrm{rpm}$ and $37 \pm 0.5^{\circ} \mathrm{C}^{22}$

\section{Features of SMMDF}

- It is free from obstructions.

- It gives good mucoadhesion.

- It gives rapid disintegration (within 5-30 sec).

- It releases the drug quickly.

\section{Advantages of SMMDF}

- Quick onset of action as compared to tablet.

- Does not require water during administration.

- Taste masking is possible by using different sweetening agents.

- There is no risk of chocking.

- It offers good stability.

- It offers patient compliance.

- Rapid disintegrating and dissolution.

- Flexible and portable nature gives ease in transportation, storage, and handling.

- Avoids first past metabolism.

\section{Disadvantages of SMMDF}

- Only low dose drug can be incorporated (less than $30 \mathrm{mg}$ ).

- Dose uniformity is a challenge.

- It takes moisture from atmosphere.
- It requires special packaging for product's stability and safety. ${ }^{8}$

\section{Drug selection for SMMDF}

SMMDF is useful for Biopharmaceutical classification system BCS Class II and IV. Drug lipophilicity $(\log \mathrm{P})$ is useful for design of SMMDF. High $\log \mathrm{P}$ of drug (greater than 4) is desirable. Drugs which have low solubility in water or lipids are difficult to deliver through SMMDF. Drugs which are administered in very high dose are not suitable for formulation unless they have extremely good solubility in at least one of the components of SMEDDS, preferably in oil phase. High melting point drugs with $\log \mathrm{P}$ values of about 2 are poorly suited to SMMDF. At the other end of the spectrum, lipophilic drugs, such as cinnarizine with $\log \mathrm{P}$ values greater than 5 , are good candidate for SMMDF.

The melting point acts as a surrogate for the product of solubility and partition coefficient. It allows one to assess whether a drug is likely to be well absorbed or not at a given dose level. In general, low melting compounds will be better absorbed than high melting point compounds. For every one hundred degrees increase in melting temperature, there is a 10 -fold decrease in the maximum dose that will provide at least $50 \%$ absorption. So low melting point and low dose of drug is desirable for formulation of SMEDDS and SMMDF.

Examples of drug that can be used for formulation of SMMDF are Anticancer (Paclitaxel), Antihyperlipidemic (Fluvastatin, Ezetimibe), Immunosuppressive (Rapamycin, Cyclosporine), Antihypertensive (Nifedipine), Analgesic (ibuprofen, Naproxen, Piroxicam, Meloxicam, Indomethacin), Hormones (Progesterone, Testosterone), Antiviral (Acyclovir), Immunomodulatory (Melatonin), Antimalarial (Artemether), antidiabetic (glibenclamide). ${ }^{23}$

\section{Manufacturing methods of SMMDF}

Manufacturing methods are same as that of mouth dissolving film (Figure 1).

Solvent Casting Method: Dissolve the water soluble polymers in suitable solvent and Dissolve the drug along with other excipients in suitable solvent. Mix and stir both solutions and caste into the Petri plate and dry. Semisolid Casting Method: Dissolve the water soluble polymers in suitable solvent. Add this solution to a solution of acid insoluble polymer (E.g. cellulose acetate phthalate, cellulose acetate butyrate). The ratio of the acid insoluble polymer to film forming polymer should be 1:4. Add appropriate amount of plasticizer to obtained gel mass. Cast gel mass into the films or ribbons using heat controlled drums. 


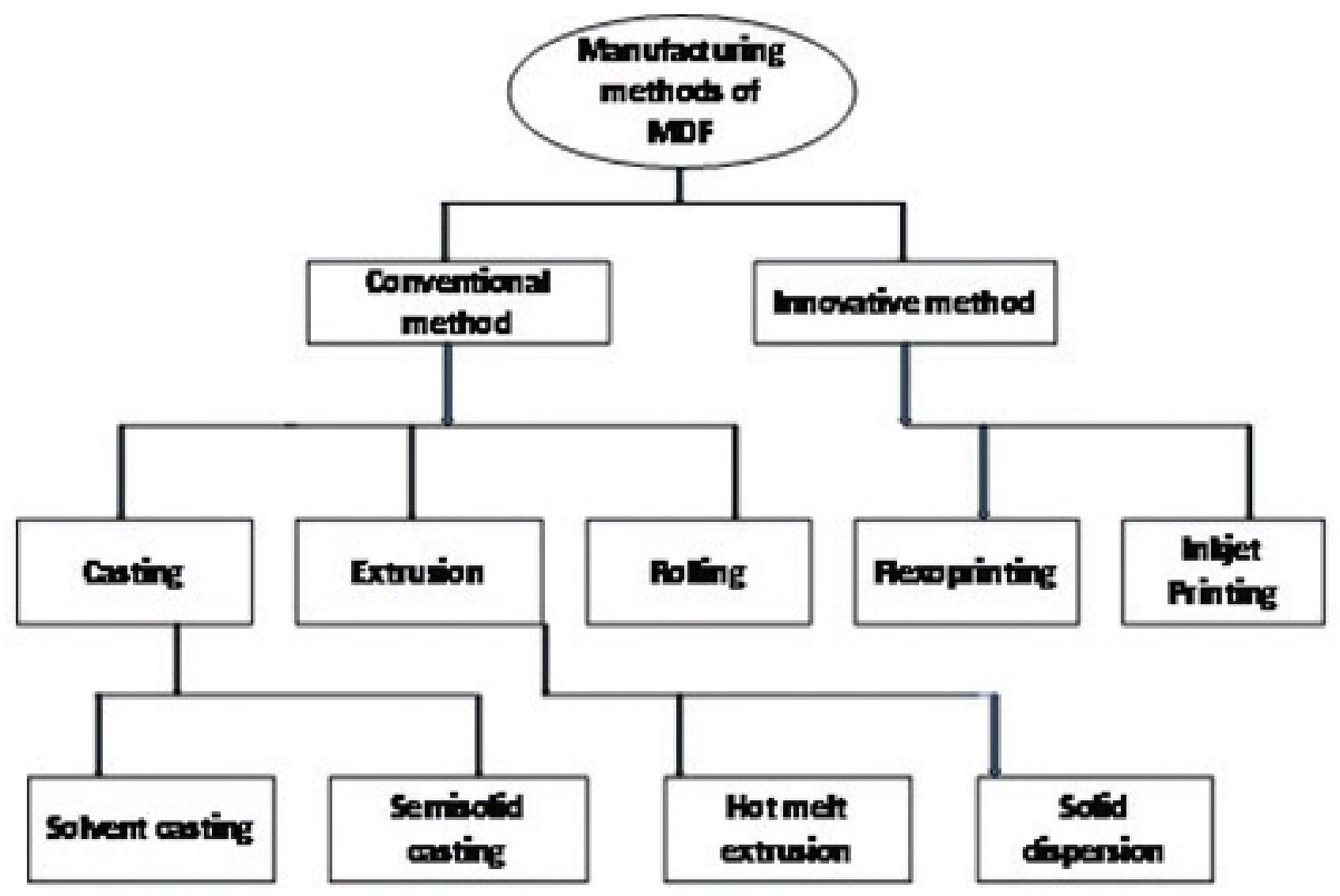

Figure 1: Manufacturing methods of Mouth dissolving film.

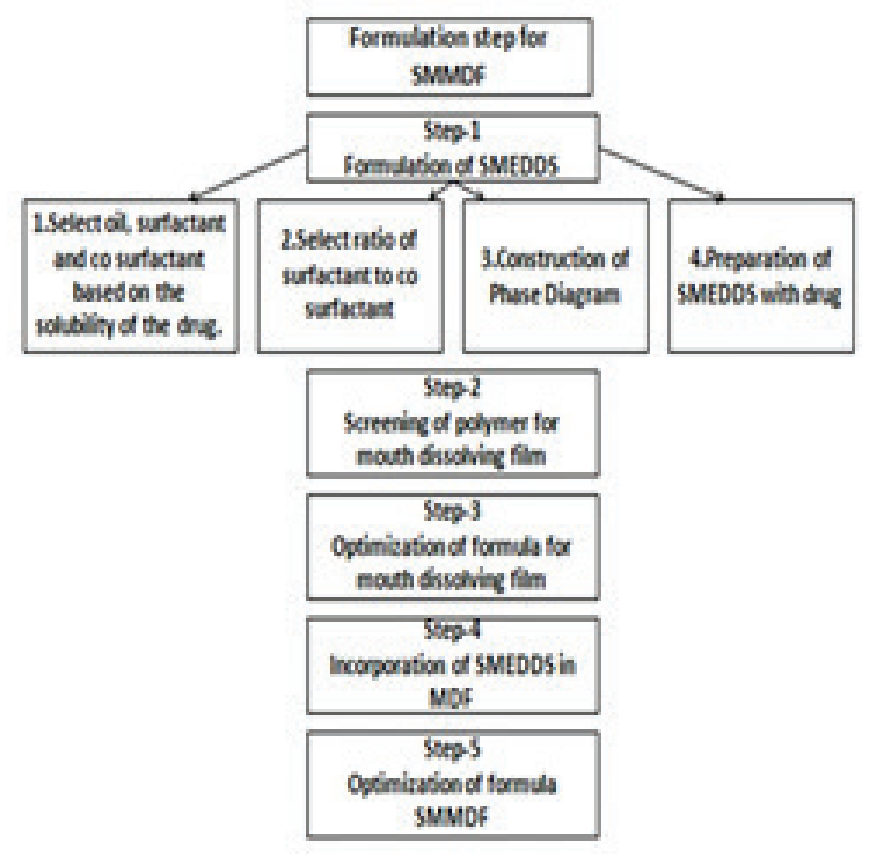

Figure 2: Formulation step for SMMDF. 
Table 3: Some patents related to Mouth dissolving films

\begin{tabular}{|l|c|c|c|}
\hline \multicolumn{1}{|c|}{ Title } & Inventor & Patent number & Issued on \\
\hline $\begin{array}{l}\text { High-content fast dissolving film with masking of bitter taste comprising } \\
\text { sildenafil as active ingredient }\end{array}$ & Jeong et al & EP2821066 & 2015 \\
\hline Fast-dissolving oral film preparation comprising aripiprazole & Kim et al & EP2883540 & 2015 \\
\hline Process for manufacturing a resulting pharmaceutical film & Yanget al. & US8906277 & 2014 \\
\hline PH sensitive compounds in taste masking within oral thin film strips & Schobel et al & EP2509631 & 2014 \\
\hline Film comprising nitroglycerin & Todd Maibach & US20100215774 & 2010 \\
\hline Disintegratable films for diagnostic devices & Meathrelet al & US7727466 & 2010 \\
\hline Thin film strip & Berry et al & US7241411 & 2007 \\
\hline Orally distintegrating formulation and process for preparing the same & Liet al & US0092564 & 2007 \\
\hline Fast dissolving orally consumable films & Leung et al & US7025983 & 2006 \\
\hline Quickly soluble film preparations & Yasuda et al & US0147653 & 2005 \\
\hline
\end{tabular}

Hot Melt Extrusion: Mix the drug with carriers in solid form. Extrude this mixture with heater melts of Extruder. Shape the melted mixture in films by the dies.

Solid Dispersion Extrusion: Dissolve drug in a suitable liquid solvent. Incorporate drug solution into the melt of polyethylene glycol, below $70^{\circ} \mathrm{C}$. Shape Solid dispersions into the films by means of dies.

Rolling Method: Roll a suspension containing drug on a carrier. The solvent is mainly water and mixture of water and alcohol. Dry the film on the rollers and shape as desire.

\section{Flexoprinting or Flexographic printing technology}

(FPT): FPT is a process that transfers drug into thin films gently via contact printing. The flexographic printing is a rotary printing process. Measure ink consisting of drug substance solution and suspension by an anilox roller then are transferred to a printing cylinder that prints the film after unwinding the daughter roll. It is useful for heat sensitive products like proteins and peptides. The production efficiency is high as the production rate of 530 oral films per minute. Hence this process is used to scale-up production.

Inkjet printing: Inkjet printing is the recently developed technology, which is characterized by its versatility, accuracy, repeatability and relatively inexpensive method that deposits small volumes of solution in films. Inkjet printing is extensively applicable for the preparation of low dose drug and also offers an opportunity to manufacture personalized medicines. Dissolve the drug in a solution (ink) with optimal properties (viscosity and surface tension) for printability. After deposition by printing, Separate the printed patterns by cutting and inserting into capsule shells or folded to form the final therapeutic dosage forms or coated in an appropriate manner. ${ }^{24}$

\section{Formulation steps for SMMDF}

Figure 2 gives idea about formulation of SMMDF. Evaluate polymer according to Film forming capability. Choose the polymer which gives proper disintegration time with good film forming capability. Optimize the quantity for polymer and plasticizer. Prepare casting solution by dissolving polymer, plasticizer, sweetener, flavor, and color in water. Transfer appropriate volume of SMEDDS solution containing drug into a casting solution. Mix it well. Remove air that entrapped in solution. Dry the casting solution in Petri plate. Cut dosage form into proper size to obtain the desired amount of drug. Pack and store in aluminum foil.

\section{Evaluation of SMMDF}

Film thickness: This is essential to ascertain uniformity in the thickness of the film as this is directly related to the dose in the strip. Calculate film thickness by using micrometer screw gauge at 5 different strategic locations. ${ }^{25-27}$

Tensile strength: Evaluate tensile strength of the patch by using the tensilometer. It consists of two load cell grip, the lower one is fixed and upper one is movable. Film with dimensions of $2 \times 2 \mathrm{~cm}^{2}$ is fixed between cell grips and force gradually applied till the film break. Take tensile strength reading directly from the dial in $\mathrm{kg}^{.26}$ Calculate tensile strength by following equation: Tensile strength $=\mathrm{F} / \mathrm{A}$

Where, $\mathrm{F}=$ Break force, $\mathrm{A}=$ Area of strip in $\mathrm{mm}^{2}$.

Folding endurance: Determine folding endurance by repeated folding of the strip at the same place till the strip breaks.

Disintegration time: Keep six strips in the disintegration tester at room temperature in tubes in the environment of water until they disintegrate and measure time. Disintegration time will vary depending on the formulation 
but typically the disintegration range is from 5 to 30 seconds.

In vitro drug release test: Perform in-vitro drug dissolution of SMMDF using USP paddle apparatus. Carry out the studies at $37^{\circ} \mathrm{C}$ with stirring speed of $75 \mathrm{rpm}$ in $900 \mathrm{ml}$ phosphate buffer ( $\mathrm{pH}$ 6.8). Withdraw $5 \mathrm{ml}$ of samples at predetermined time intervals of $2,4,6$, $8,10 \mathrm{~min}$ and replace with the same volume of buffer. Collect the samples and determine the concentration at appropriate wavelength using UV-visible spectrophotometer. ${ }^{27,28}$

Drug content: Perform the drug content test to ensure uniform distribution of drug. Place each film unit in $10 \mathrm{ml}$ of volumetric flask containing solvent. Obtain homogenous solution with constant stirring and filter. Determine the drug content by UV after proper dilution. ${ }^{28}$ Droplet size of reconstituted micro emulsion: Assess the average droplet size, size distribution and polydispersibility index of micro emulsion from liquid SMEDDS and from SMMDF by correlation spectroscopy. Morphological analysis of SMMDF by SEM- Investigate the outer surface characteristics of SMMDF by SEM. Solid state characterization of SMMDF by FTIR, DSC and X-RD: Determine drug-excipient compatibility by the use of FTIR. Use DSC to verify the interaction of drug and other excipients. Use X-RD to verify the physical state of drug in SMMDF. ${ }^{2}$ Table 3 gives information related to Mouth dissolving film patents.

\section{CONCLUSION}

Self-emulsifying mouth dissolving film is promising approach for the formulation of drugs with poor aqueous solubility, high molecular weight, pre systemic first pass effect, enzymatic degradation, gastric irritation, limited dissolution rate and low bioavailability. SMMDF is used to improve dissolution characteristics of a poorly water soluble drug as it maintains the drug in a solubilized form and has quick onset of action. Solid-SMEDDS is also a solid dosage form but it cannot avoid first pass metabolism of drug. SMMDF is economic as it requires less quantity of drug and less complicated machineries. SMMDF appear to be unique and industrially feasible approach to overcome the problem of low oral bioavailability associated with the lipophilic drugs. This study explores the possibilities of loading a wide variety of plant actives as their scale up is convenient and economical.

\section{AKNOWLEDGEMENT}

The authors are grateful to department of Pharmacy, Banasthali University, Banasthali, Rajasthan for their valuable support for this paper.

\section{CONFLICT OF INTEREST}

The author have no conflict of interest to declare.

\section{ABBREVIATION USED}

SMMDF: Self micro-emulsifying mouth dissolving film; SMEDDS: Self micro emulsifying drug delivery system; MDF: Mouth dissolving film; ODT-orally disintegrating tablet.; OTF: Oral thin film; ODF: Orally disintegrating films, Orodispersible film; LBDDS: Lipid-based drug delivery system; SEDDS: Self emulsifying drug delivery systems; GIT: Gastrointestinal tract. PDI-Polydispersity Index; FTP: Flexographic printing technology; XRD: X-ray Diffraction; DSC: Differential scanning calorimetry; UV: Visible spectrophotometerUltraviolet visible spectrophotometer.

\section{REFERENCES}

1. Irfan $\mathrm{M}$, et al. Orally disintegrating films: A modern expansion in drug delivery system. SPJ. 2015.

2. Lu Xiao, Tao Yi, Ying Liu. A new self microemulsifying mouth dissolving film to improve the oral bioavailability of poorly water soluble drugs. Drug Dev Ind Pharm. 2013;39(9):1284-90. http://dx.doi.org/10.3109/03639045.2012.7237 16 ; PMid:23009066.

3. Alshehri SM, et al. Mefenamic acid taste-masked oral disintegrating tablets with enhanced solubility via molecular interaction produced by hot melt extrusion technology. J Drug Deliv Sci Technol. 2015;27:18-27. http://dx.doi. org/10.1016/j.jddst.2015.03.003 ; PMid:25914727 PMCid:PMC4404746.

4. Nagy ZsK, Nyúl K, Wagner I, Molnár K, Marosi. Electrospun water soluble polymer mat for ultrafast release of Donepezil $\mathrm{HCl}$. Express Polym Lett. 2010;4(12):763-72. http://dx.doi.org/10.3144/expresspolymlett.2010.92.

5. Malke M, Shidhaye S, Kadam VJ. Formulation and evaluation of Oxacarbazine fast dissolving tablet. Indian J Pharm Sci. 2007;69(2):211-4. http://dx.doi.org/10.4103/0250-474X.33145.

6. Jeong SH, Takaishi Y, Park Fu K. Material properties for making fast dissolving tablets by a compression method. J Mater Chem. 2008;18(30):3527-35. http://dx.doi.org/10.1039/b800209f.

7. Banker GS. Film coating Theory \& Practice. J Pharm Sci. 1966;55:81-9. http://dx.doi.org/10.1002/jps.2600550118; PMid:5918657.

8. Bala R, Pawar P, Khanna S, Arora S. Orally dissolving strips: Anew approach to oral drug delivery system. Int J Pharma Investig. 2013;3(2):67-76. http://dx.doi. org/10.4103/2230-973X.114897; PMid:24015378:PMCid:PMC3757902

9. Jani R, Patel D. Hot melt extrusion: An industrially feasible approach for casting orodispersible film. AJPS. 2015;10(4):292-305. http://dx.doi. org/10.1016/j.ajps.2015.03.002.

10. Chowdary KPR, Hymavathi $\mathrm{R}$ et al. Enhancement of dissolution rate of meloxicam. J Pharm Sci. 2001;63(2):150-4.

11. Sharma D, Soni M, et al. Solubility Enhancement-Eminent Role in Poorly Soluble Drugs. Res J Pharm Technol. 2009;2(2):220-4.

12. Kalepu S, Mohanvarma M, Padavala V. Oral lipid-based drug delivery systems-An overview. Acta Pharm Sin B. 2013;3(6):361-72. http://dx.doi. org/10.1016/j.apsb.2013.10.001.

13. Liuqing Di, Xiaolin B, Xuan Liu, Qiang Zu, Improved Oral Bioavailability Using a Solid Self-Microemulsifying Drug Delivery System Containing a Multicomponent Mixture Extracted from Salvia miltiorrhiza, Molecules. 2016;21(4):456. http://dx.doi.org/10.3390/molecules21040456; PMid:27070565.

14. Pandya BD, Shah SH, Shah N. Bioavailability Enhancement of Poorly Soluble Drugs by Self Micro Emulsifying Drug Delivery System (SMEDDS): A Review J Pharm Sci Bio Scientific Res. 2015;5:187-96.

15. Verma A, Singh MK, Kumar B, Development and characterization of flutamide containing self-microemulsifying drug delivery system (SMEDDS). Int J Pharm Pharm Sci. 2011;3:60-5. 
16. Patel MJ. A self-microemulsifying drug delivery system (SMEDDS). Int J Pharm Sci Rev Res. 2010;4:29-35.

17. Shen-Fu Lin, Ying-Chen Chen, Hsiu-O Ho, Wei-Yu Huang, Ming-Thau Sheu, Der-Zen Liu. Development and characterization of dilutable selfmicro emulsifying premicroemulsion systems (SMEPMS) as templates for preparation of nanosized particulates. Int J Nanomedicine. 2013;8:3455-66. PMid:24049445 : PMCid:PMC3775676.

18. Vincent Jannin, et al. Development of self emulsifying lipid formulations of BCS class II drugs with low to medium lipophilicity. Int J Pharm. 2015;495(1):38592. http://dx.doi.org/10.1016/j.ijpharm.2015.09.009 ; PMid:26364710.

19. Bora D, Borude P, Bhise K. Formulation and Evaluation of Self microemulsifying drug delivery systems of low solubility drug for enhanced solubility and dissolution. AJBPS. 2012;2(15):7-14.

20. Pattewar S, Kasture S, Pande V, Sharma S. Self Microemulsifying Drug Delivery System: A Lipid Based Drug Delivery System. Int J Pharm Sci Res. 2016;7(2):443-52.

21. Sarpal K, et al. Self-emulsifying drug delivery systems: A strategy to improve oral Bioavailability. CRIPS. 2010;11:42-9.

22. Jaiswal JJ, Solanki AJ, Yadav SK. A Review on Solid-Selfmicroemulsifying Drug Delivery System: Formulation Strategies to Improve the Bioavailability of Poorly Soluble Drugs J Pharm Sci Bioscientific Res. 2016;6(3):239-46.

23. Chu KA, Yalkowsky SH. An interesting relationship between drug absorption and melting point. Int J Pharm. 2009;373(1):24-40. http://dx.doi.org/10.1016/j. ijpharm.2009.01.026; PMid:19429285.

24. Karki S, Kim H, Na SJ, Shin D, Jo K, Lee J. Thin films as an emerging platform for drug delivery. Asian Journal of Pharmaceutical Sciences. 2016:1-50.

25. Lai Francesco et al. Maltodextrin fast dissolving films for quercetin nanocrystal delivery: A feasibility study. Carbohydr Polym. 2015;121:217-23. http://dx.doi. org/10.1016/j.carbpol.2014.11.070 ; PMid:25659692.
26. Vishwakarma D, Tripathi A, Maddheshiya B. Review article on mouth dissolving film. JGPT. 2011;3(1):1-8.

27. Anil M. Pethe AM, Desai RB. Formulation, optimization \& evaluation of mouth dissolving film of nifedipine by using design of experiment. Asian Journal of Pharmaceutical Sciences. 2016;11(1):74-6. http://dx.doi.org/10.1016/j. ajps.2015.10.059.

28. R. Gowri, N. Narayanan, S. Revathy, P. Prabhavathy, G. PreethyMol, G. Rekha. Melt in mouth films -an effective alternative drug delivery system. IJBPR. 2013;4(9):645-50.

29. Jeong $\mathrm{HJ}$ et al. High-content fast dissolving film with masking of bitter taste comprising sildenafil as active ingredient. EP2821066, 2015.

30. Yong SK, Jun HS. Fast-dissolving oral film preparation comprising aripiprazole. EP2883540, 2015.

31. Yang RK, Fuisz RC, Myers GL, Fuisz JM. Process for manufacturing a resulting pharmaceutical film.US8906277,2014.

32. Schobel AM, Davidson K, Miloshoff L, Sanghvi P, Hariharan M. PH sensitive compounds in taste masking within oral thin film strips. EP2509631, 2014.

33. Todd Maibach. Film comprising nitroglycerin. US20100215774,2010.

34. Meathrel WG et al. Disintegratable films for diagnostic devices. US7727466, 2010.

35. Berry CJ, Klauser W. Thin film strip. US7241411, 2007.

36. Li H, Wang H, Wang M, Wang L. Orally distintegrating formulation and process for preparing the same. US7815935,2007.

37. Leung et al. Fast dissolving orally consumable films. US7025983,2006.

38. Yasuda K, Okubo T, Sawai Y. Quickly soluble film preparations. US0147653,2005.

\section{SUMMARY}

- A self micro-emulsifying mouth dissolving film (SMMDF) is a dosage form which is based on mouth dissolving film integrated with self micro emulsifying components. Self-emulsifying mouth dissolving film is promising approach for the formulation of drugs with poor aqueous solubility, high molecular weight, pre systemic first pass effect, enzymatic degradation, gastric irritation, limited dissolution rate and low bioavailability. SMMDF is economic as it requires less quantity of drug and less complicated machineries. SMMDF appear to be unique and industrially feasible approach to overcome the problem of low oral bioavailability associated with the lipophilic drugs. 